\title{
Research on Key Technologies and Device of Rescue for Mine Dynamic Disaster
}

\author{
Jun Guo 1,2,3,a , Yin Liu 1,2,3, Yongfei Jin 1,2,3, Xuezhao Zheng ${ }^{1,2,3}$, Wenyong \\ Liu $^{1,2,3}$ \\ ${ }^{1}$ College of Safety Science and Engineering, Xi'an University of Science and Technology, Xi'an, \\ Shanxi 710054, PR China; \\ ${ }^{2}$ Key Laboratory of Western Mine and Hazard Prevention, Ministry of Education of China, Xi'an, \\ Shanxi 710054, PR China; \\ ${ }^{3}$ State Mine Emergency Rescue (Xi'an) Research Center, Xi'an, Shanxi 710054, PR China \\ aguojun@xust.edu.cn
}

Keywords: Mine dynamic disaster, Multimedia technology, Mine rescue, Drilling detection

Abstract: With the increase of mining depth, dynamic disaster is more severe, which is a serious threat to the safety of miners. Because of complex mine geological structure, and relatively junior safety facilities, tunnel collapse and other dynamic disasters are easily induced, which brought great difficulty to the rescue work. During the rescue, the original mine monitoring and communication device of mine, and regular ground communication and detection technology cannot work properly. Therefore, the location of the trapped miners and the real situation of the disaster area would not be grasped by rescue workers. Therefore, several key technologies were adopted to develop the drilling hole detection device for multiple information after mine disaster, such as the Symmetric Digital Subscriber Line (SDSL) cable transmission technology, the integrated technology that includes of the dual-stream technology, hierarchical synchronization method and timestamp synchronization method, a multimedia relay remote transmission technique combining wireless dual band Mesh network and SDSL cable transmission. Based on technologies above, the drilling detection system was developed, and achieved the real-time remote transmission of image and sound, gas parameters and other key information. The detection system could be used in searching on miners in distress, fault diagnosis of large diameter drilling hole, real-time and dynamic monitoring of environmental parameters in underground disaster area. This device was successfully applied in the rescue work of the mine dynamic disaster accident, which happened on Dec.25, 2015, the Yurong gypsum mine collapsed in Pingyi County, Shandong province, PR China.

\section{Introduction}

The mine dynamic disaster is one of the most significant safety hazards in coal industry (Wang, Y.G. et al, 2010). As the depth and intensity of coal mining increase in recent years, shallow coal resources start to deplete. In some mining area, such as Huainan coalfield and Yangzhou coalfield, the average mining depth reaches over $750 \mathrm{~m}$ and continues to increase by $15-25 \mathrm{~m}$ annually associated with high risk of mine dynamic disasters. This poses a serious threat to the safety of production and miners and lead to the major economic losses and serious severe adverse social 
effects(JIN,Y.F. et al, 2015). The mine dynamic disasters, including rock burst, coal and gas outburst and water inrush, are all induced by the mining and other common underground engineering activities(WEN,H. et al, 2017). Generally, these disasters are characterized by suddenness, high uncertainty, graveness, destructiveness and usually cause a massive number of casualties and equipment damage, and even to block up the roadway, destroy the ventilation system and result in a bigger disaster (Qiu, J.B., 2012). The first mine dynamic disaster in 1993 appeared in Shengli Coal Mine located in the Fushun, Liaoning Province. Although these disasters appeared relatively later than other countries, but showed a rapid growth trend. So far, various types of mine dynamic disasters have occurred in hundreds of coal mines and non-coal mines and this tendency is increasingly serious with the growth of mining depth.

In general, in order to save the trapped miners out from the underground roadway timely after the occurrence of mine dynamic disaster, the horizontal rescue technology is the most commonly used method. It can be summarized that rescue crews get close to the trapped miners along with the tunnel to with the help of traditional methods, such as shouting, tapping, people tracing instrument and life detector system, eventually to rescue the trapped people successfully. However, this horizontal rescue method will be limited when the tunnel collapsed. Under such circumstances, the vertical rescue technology would be the most suitable rescue method, which could be described as follows. Firstly, a series of boreholes from the ground surface was constructed direction to the trapped miners. Then oxygen, food and water were transport through these boreholes to support the basic living of the trapped miners until they were freed through the large-diameter boreholes $(\mathrm{Wu}$, Y.Y., 2013). This method has been successfully used in the rescue of mine dynamic disaster many times. Both in the rescue of copper mine accident in San Jose, Chile and Gypsum mine collapse accident in Pingyi, Shandong Province, this vertical rescue technology has taken an important role for saving the trapped miners out successfully.

In the process of the mine dynamic disaster rescue, it is necessary for the trapped workers to be monitored constantly. Only in this way, the real time physical condition of trapped workers can be transferred to command center for setting scientific and reasonable rescue plan. At the same time, the multimedia communication technology can transmit real-time parameters such as the image, sound and environment, to the ground to provide reliable underground information.

\section{Mine dynamic disaster}

In the process of mining, a variety of dynamic disasters will occur in mining area with the character of complex geological structure, high geostress and activate fracture. The common forms of typical dynamic disasters can be performed as mine outburst, mine water gushing, geothermal disaster, shaft rupture, root collapse, rock burst, coal (rock) and methane outburst-prone mines, coal bumps and roadway collapse, etc. On the ground, those disaster perform as mine earthquake, ground subsidence, ground collapse, ground cracks, slope failure, etc. (Qi, Q.X., et al, 2003). Among them, the impact of coal bumps or goaf collapse lead to mining-induced seismicity, and then lead to roadway collapse that is a common dynamic disaster type of mine dynamic disaster. 
As one of the most common types of dynamic disasters, mining seismicity will lead to a series of secondary disasters, which threaten the safety production of mine. Due to the shallow seismic source and high intensity, it is easy to cause casualties and equipment damage (Jiang, F.X., et al, 2009). Secondly, the damage caused by mining seismicity occurs rapidly, the precursor is not obvious, so it is difficult to forecast (Chen, S., 2009). In China, due to the complex geological structure, long service period of roadway and the relatively backward safety facilities, dynamic disaster easily lead to collapse of the roadway, and bring lots of difficulty for disaster relief work. In the rescue of mine dynamic disaster, due to the destruction of the disaster, coupled with complex underground environment, limited space, the original mine monitoring, communication and ground commonly communication and detection equipment used in the underground cannot work, rescue workers cannot find accurately the location of trapped miners and know the status of the disaster area.

\section{Research and development of rescue detection equipment}

\section{Key technologies of multimedia communication}

Multimedia communication technology combines multimedia technology with communication technology effectively, which overcomes the drawbacks of the original emergency communication technology for rescue in mine, and is playing a more and more important role in the rescue (Sun, J.P., 2013). The key technologies including compression encoding technology, media synchronization technology, data transmission technology, communications equipment, explosion-proof technology, and digital multimedia acquisition technology (Li, W.F., et al, 2005).

In design scheme of this paper, first of all, SDSL cable transmission technology is adopted to solve the problem that the information collected by the detector cannot be transmitted to the ground through the drilling hole, as well as the problem of unstable information transmission (Zheng X.Z., 2004). Meantime, the integrated technology was adopted, which including of the dual-stream technology, hierarchical synchronization method and timestamp synchronization method, to solve the problem of signal transmission delay and multimedia information asynchronous (Li, X.N. et al, 2011). Besides, in order to connect detection device with the ground station conveniently and quickly, a multimedia relay remote transmission technique combining wireless dual band Mesh network and SDSL cable transmission(Huang, R. et al, 2007).

\section{Borehole detection system}

According to the needs of mine emergency rescue and the difficulties in the rescue process, the research team of professor Wen developed life information drilling detection system, who belong to the Xi'an research center of national mine rescue team. There are some functions with the detection system, like acquisition and transmission of voice, video transmission and a variety of environmental parameters from underground disaster area (Wen, H. et al, 2011). The composition of the system is shown in Figure 3, including 4 parts: the borehole life detector, the high strength transmission cable, the ground dual wireless signal transmission control wheel, the computer only for the probe system. Among them, the detector and the wire spool are connected by twisted pair wire, the computer and the wire spool are linked by wireless for signal transmission, so as to carry 
out the rescue detection work as soon as possible. After the accident, the system can be used in getting many information for rescue command decision, such as searching the trapped miner in the underground, and realizing the two-way transmission of audio and video. What's more, the system can also be used in Exploration of underground roadway space, supporting facilities, and water damage, and rescue drill hole collapse, water gushing, clogging residue etc.

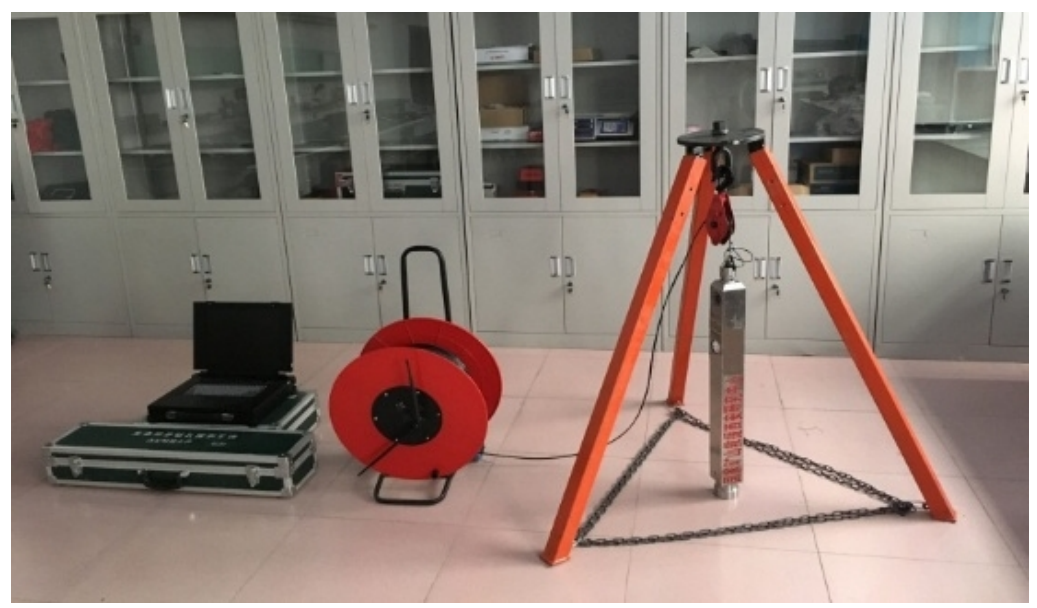

Fig. 1 The composition diagram of the life information drilling detection system

\section{Application of collapse accident in Shandong gypsum mine}

The 12.25 Wanzhuang gypsum mine collapse accident occurred in Pingyi County, Shandong Province on December $25^{\text {th }}, 2015$. The large-scale underground roadway collapse caused the equivalent of 4 . 0 earthquake quake, resulting in 29 workers were trapped (Anonymity, 2016). Response to the request by the National Mine Emergency Rescue Command Center, professor Wen and his colleagues five peoples went to the scene. They adopted the life information drilling detection system developed by team independent research and development successfully found out 4 trapped people through small diameter drilling holes. Besides, communicating with them by sound and video system, timely grasp the status of the four trapped people and underground disaster area. In the following rescue, the system was used in exploring the large diameter life-saving drilling, gushing water in borehole and the underground environment for the rescue headquarters to provide timely and accurate information.

\section{Underground trapped people searching}

On December 30, in 2015, four trapped miners were found by using the life information drilling detection system. Communicating with them with sound, video system, timely grasp of the four trapped physical condition and underground disaster situation. Currently, in the rescue command observation of the processor of the situation through the computer real-time, example for the figure $4 \mathrm{a}$; As it shown in figure $4 \mathrm{~b}$, the detection system found a trapped miner, a miner's hand-held miner's lamp appeared in the detection screen; the director who in the National Rescue Command Center, through the detection system made a real-time call with the underground trapped miners to appease the trapped miners Understand the downhole situation, as shown in Fig. 4c. 


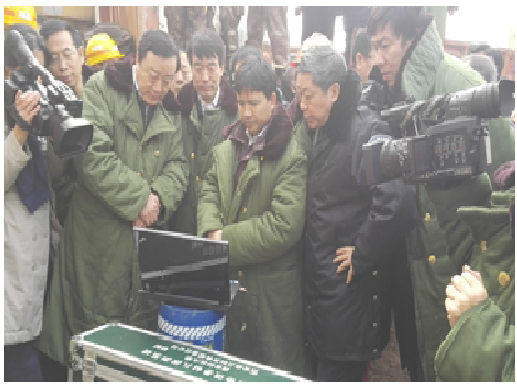

a)

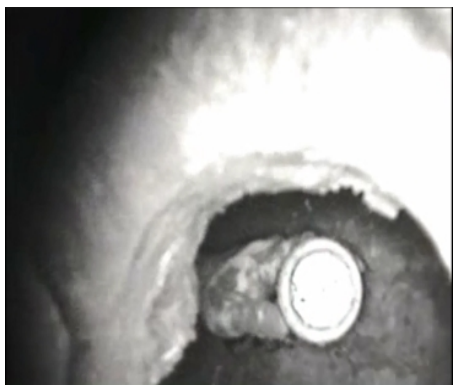

b)

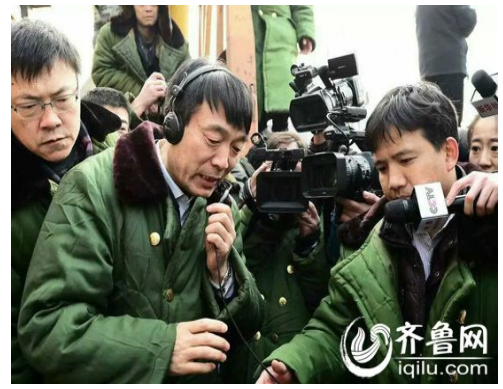

c)

Fig. 2 The trapped people were searched and communicated by detection system

\section{Life - saving drilling detecting}

In the following process of rescue, using life information drilling detection system detected the drill hole drilling situation, drilling mud and water level and other information can Provides valuable information access to the relevant drilling information for the command of the adjustment of rescue programs and drilling construction program for the success of large diameter drilling has played an important role. Fig. 5a and $5 \mathrm{~b}$ respectively show the video screenshots of the gushing and clogging of the drilling holes obtained by the detection system.

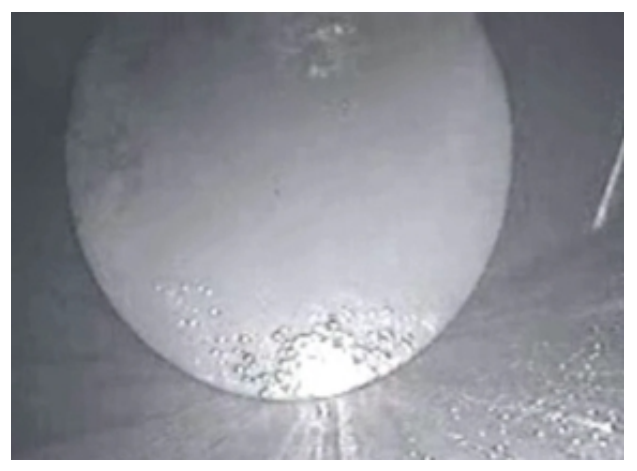

a)

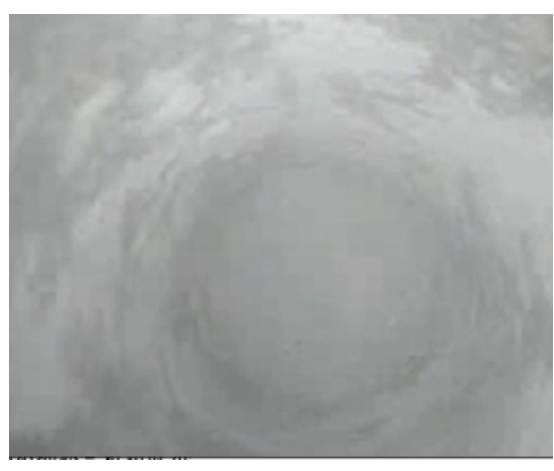

b)

Fig.3 The drill hole status probed by detection system

\section{Overview of underground tunnel}

Through the life information drilling detection system, rescue workers communicated with workers trapped in underground. With the help of trapped workers, some situations were detailed probed, like the underground roadway space, water gushing and rock breaking. Through HD video data acquired by detection system, the real situation of the underground environment and trapped people was grasped. This data provided reference for analysis of dynamic disaster development and timely adjust the rescue plan and decision-making. The pictures as shown in Figure 6 are the two screenshots of video, showing the status of the underground tunnel and its roof. 

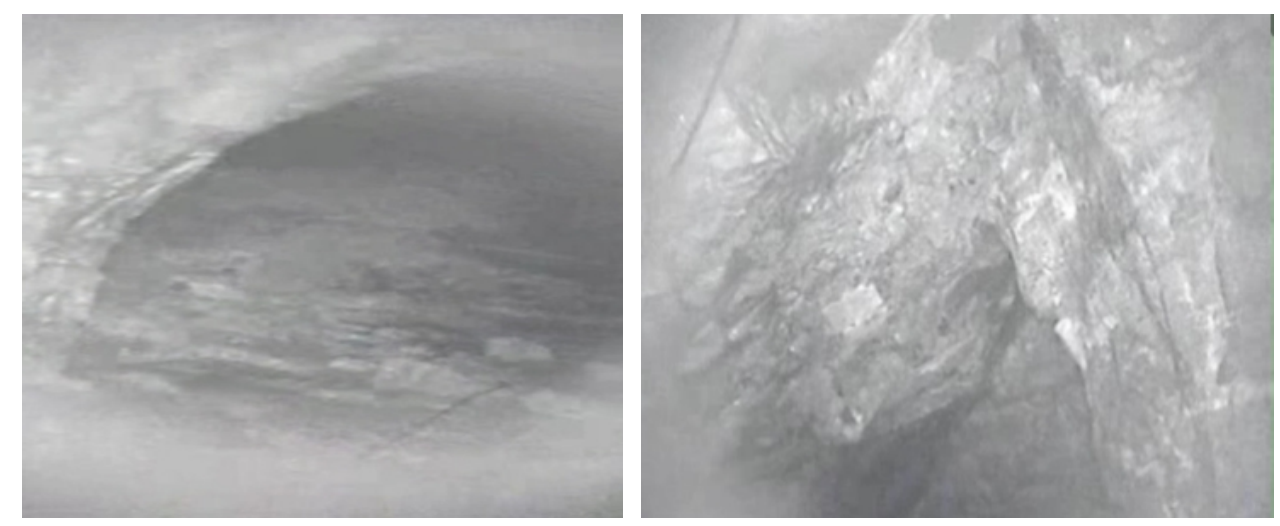

Fig.4 The underground tunnel status probed by detection system

\section{Conclusions}

Dynamics disaster in mine has become an important factor restricting the safe production of coal mines and non-coal mines in China. With the increase of mining depth in mine, the horizontal and the vertical stresses on roadway will lead to large deformation, the mine earthquake and rock burst would happen more easily, resulting in the collapse of the roadway, and posing a great threat to the lives of underground workers.

Life information drilling detection system based on multimedia communication technology plays an important role in the collapse of the Wanzhuang gypsum mining area in Pingyi County, Shandong Province. This detection system could be used in the status of disaster area and trapped people, so that effectively reduce the number of casualties, improve the efficiency of the rescue.

After dynamics hazards in mine happened, the roadway leading to the disaster area is often collapsed and blocked, rescue workers are unable to truly grasp the situation of the disaster area and trapped people, making the rescue task is very difficult. The development of multimedia communication technology used in mine rescue will play a vital role in the rescue process.

\section{Acknowledgements}

This research work was financially supported by the following funds: The National Natural Science Foundation of China (51404195); Key Project of National Natural Science Foundation of China (51134019); China Postdoctoral Science Foundation (2014M552466).

\section{References}

[1] Wang, Y.G., Wei, J.P., Sun, H.T., Mechanism analysis and prevention of coal and rock dynamic disaster, Mining Safety \& Environmental Protection, 37,2(2010), 17-19.

[2] JIN,Y.F, GUO,J, WEN,H, et al. Experimental study on the high temperature lean oxygen oxidation combustion characteristic parameters of coal spontaneous combustion[J]. Journal of China coal society, 2015,(03):596-602. 
[3] WEN,H, GUO,J, JIN,Y.F, et al. Experimental study on the influence of different oxygen concentrations on coal spontaneous combustion characteristic parameters[J].Int. J. Oil, Gas and Coal Technology,2017, 16(2):187-202.

[4] Qiu, J.B., Study on the technology of dynamic disaster source detection in underground coal mine, Master Thesis, Inner Mongolia University of Science and Technology, 2012.

[5] Wu, Y.Y., Study on the technical of the rapid vertical drilling rescue in the accident of water inrush in Wangjialing Coal mine, Proceedings of the 2013 annual meeting of China Occupational Safety and Health Association, 2013.

[6] Qi, Q.X., Mao, D.B., Wang, Y.X., Analysis on the occurrence mechanism and control methods of mine geological dynamic disasters, Geology and exploration, 39(2003), 94-97.

[7] Jiang, F.X., Wang, P., Feng, Z.Q., Mechanism, prediction and control of "rock burst induced by shock bump"kind dynamic accident in composite thickness coal, Journal of China Coal Society, 12 (2009), 1605-1609.

[8] Chen, S., Study on rockburst monitoring and orientation system in deep stope, Master Thesis, Liaoning Technical University, 2009.

[9] Sun, J.P., Modern mine communication technology and system, Industry and Mine Automation, 39, 3(2013), 1-5.

[10] Li, W.F., Zheng, X.Z., An Emergency Communication Technology of Multimedia Used in Mine Rescue, Modern Electronic Technique, 28,22(2005), 43-45.

[11] Zheng, X.Z., The research of Mine-Visualizing Rescue commanding Instrument, Ph.D. dissertation, Xi'an University of Science and Technology, 2005.

[12] Li, X.N., Chen, H.X., Sun, Y., Embedded audio-video synchronization coding based on H. 264, Journal of Jilin University ( Engineering and Technology Edition),41,5,(2011), 1475-1479.

[13] Huang, R., Zou, C., Research of the Code in the COFDM (Code Orthogonal Frequency Division Multiplexing), Ship Electronic Engineering, 4(2007), 86-89.

[14] Wen, H., Deng, J., Wu, J.B., Life information drilling detection system, Chinese patent, (2011).

[15] Anonymity, the accident report of rescue work of "12.25" gypsum mine collapse at Pingyi Shandong, China Emergency Management, 1(2016), 47-48. 